\title{
Studies on the Mechanism of Action of Unsaturated Fats on Cholesterol Metabolism in the Rabbit*
}

\author{
Fredrick A. Bieberdorf and Jean D. Wilson $\dagger$ \\ (From the Department of Internal Medicine, The University of Texas Southwestern Medical \\ School, Dallas, Texas)
}

The original observation by Kinsell and his associates ( 3 ) and by Groen and his associates (4) that the feeding of saturated fats results in an elevation whereas the feeding of unsaturated fats causes a lowering of serum cholesterol has been confirmed repeatedly in both man (5-7) and experimental animals $(7-10)$. Theoretically, unsaturated fats might produce a lowering of serum cholesterol in at least four ways: by increasing the excretion or degradation of cholesterol, by inhibiting cholesterol synthesis, by interfering with the absorption of cholesterol, or by effecting a redistribution of cholesterol between serum and tissues either directly or via an influence on lipoprotein metabolism. Previous attempts to elucidate the mechanism or mechanisms responsible for this action have not demonstrated any consistently reproducible effects either on cholesterol excretion or degradation (11-15) or on cholesterol synthesis (16-20), and consequently it has been suggested by exclusion that unsaturated fats cause a redistribution of cholesterol between serum and the tissues (15). However, attempts to demonstrate directly that a shift of cholesterol occurs under circumstances of isocaloric fat substitution have not been successful (19).

Two recent observations made it logical to reevaluate the possible mechanisms of this cholesterol-lowering effect. First, Wigand has clearly

* Submitted for publication April 29, 1965; accepted July 22, 1965.

Supported in part by grants from the American, Texas, and Dallas Heart Associations.

This work was presented at the meeting of the American Federation for Clinical Research in Atlantic City, N. J., on May 3, 1964, and has been published in abstract form $(1,2)$.

† Work performed during tenure as an Established Investigator of the American Heart Association.

Address requests for reprints to Dr. Jean D. Wilson, Dept. of Internal Medicine, The University of Texas Southwestern Medical School, Dallas, Texas 75235. demonstrated that the divergent effects of saturated and unsaturated fats on the serum cholesterol in the human can also be demonstrated in the rabbit; adult male rabbits fed a cholesterol-free, semisynthetic diet containing $8 \%$ saturated fat developed elevated serum cholesterol levels that fell when unsaturated fats were substituted isocalorically (8). Consequently, it appears that the rabbit can serve as an adequate model for the investigation of this effect. Second, a steady state isotopic technique has been recently developed in this laboratory that makes possible the simultaneous quantification of cholesterol excretion and degradation in the intact animal (21).

The present series of experiments was therefore designed to re-examine the hypocholesterolemic effect of unsaturated fatty acids by the combined use of balance techniques together with the newer quantitative isotopic methods. Evidence has been accrued in support of the view that unsaturated fats may lower serum cholesterol by causing a redistribution of cholesterol between serum and tissues.

\section{Methods}

Feeding and collection techniques. In each experiment four to eight male, albino rabbits, weighing 1.5 to $3 \mathrm{~kg}$, were allowed free access to a semisynthetic, pelleted, fatfree diet, ${ }^{1}$ to which was added $10 \%$ hydrogenated coconut oil. Each animal was placed in an individual cage floored with a loose-screen mesh wire. Blood was col-

\footnotetext{
${ }^{1}$ The diet, which was obtained from General Biochemicals, Chagrin Falls, Ohio, contained $21 \%$ vitaminfree casein, $58 \%$ sucrose, $16 \%$ non-nutritive fiber, $4 \%$ U.S.P. XIV salt mix, and added vitamins in $\mathrm{mg}$ per $100 \mathrm{~g}$ of diet: $\alpha$-tocopherol 10, calcium pantothenate 2 , choline chloride 272 , inositol 300 , menadione 0.1 , niacin 27 , pyridoxine hydrochloride 0.95 , riboflavin 0.95 , thiamine hydrochloride 0.95 , vitamin A 4.5, vitamin D 3.0, ascorbic acid $0.3, p$-aminobenzoic acid 0.2 , folic acid 0.0006 , biotin 0.00006 , and vitamin $B_{12} 0.000006$. Vitamins $A$ and $D$ were added in gelatin.
} 
lected at intervals from the ear vein for lipid analysis. After hypercholesterolemia had developed (4 to 6 weeks) each animal was fitted with a $25-\mathrm{cm}$ wooden collar as described by Kulwich, Struglia, and Pearson (22) to prevent coprophagy. Animals so treated eat normally, gain weight, and after an initial adjustment period of 12 to 18 hours appear to move around in the usual manner. After an 8- to 10-day period in the collars, feces were collected from each animal for varying periods of time.

The fat in the diet was then changed from $10 \%$ hydrogenated coconut oil to $10 \%$ corn oil, and the collections of blood and feces were continued. In the experiments to be described the isocaloric substitution of different fats in the diets had no effect on the weighed daily food intake or on the average weight gain. At the end of the experiments the rabbits were killed by bleeding, and in some experiments the carcasses were dissected for subsequent study. In two experiments muscle biopsies were taken from the posterior thigh under local anesthesia before and after the change in dietary fat.

Isotopic studies. In the studies in which the isotopic steady state was utilized for the quantification of cholesterol excretion and degradation, each rabbit was implanted subcutaneously at the beginning of the study with a gelatin capsule of cholesterol- ${ }^{14} \mathrm{C}$ containing 105 to 190 $\mathrm{mg}$ cholesterol and 1.8 to $2.5 \times 10^{7} \mathrm{cpm}$ of cholesterol-4${ }^{14} \mathrm{C}$ as previously described (21). Analyses of the specific activity of serum cholesterol were performed at intervals for periods as long as 3 months, and feces collections were performed no earlier than 8 weeks after implantation. In the experiments in which cholesterol turnover was measured, each animal was given intravenously $9.4 \times 10^{8}$ cpm of cholesterol-4- ${ }^{14} \mathrm{C}$ solubilized with the aid of Tween 20 (23) at the beginning of the collection periods, and blood samples were collected at 2-day intervals for either 26 or 40 days. The turnover times were plotted and calculated as described by Zilversmit, Entenman, and Fishler (24).

Serum cholesterol analysis. Serum cholesterol content and ${ }^{14} \mathrm{C}$ were measured by a modification of the method of Sperry and Webb (25). Serum $(0.5 \mathrm{ml})$ was added slowly to acetone-ethanol $(1: 1)$ in a volumetric flask; the mixture was carefully brought to boil, cooled, and diluted to $10 \mathrm{ml}$. The suspension was then filtered, and aliquot portions were pipetted into test tubes. Three drops of $50 \% \mathrm{KOH}$ were added with vigorous mixing, and the solutions were incubated at $38^{\circ} \mathrm{C}$ for 1 hour, after which they were neutralized to the phenolphthalein end point with $1 \mathrm{~N} \mathrm{HCl}$. Digitonides were then formed and washed as described by Sperry and Webb (25); the dried digitonides were dissolved in methanol. One aliquot was added to $10 \mathrm{ml}$ of $0.5 \%$ diphenyloxazole in toluene and assayed for ${ }^{14} \mathrm{C}$ in a Packard Tri-Carb liquid scintillation spectrometer, and one aliquot was assayed for cholesterol content. All analyses were performed in duplicate.

Fecal sterol and bile acid analyses. The fecal sterol and bile acid analyses were performed by a modification of the method of Siperstein, Jayko, Chaikoff, and Dauben (26). The feces were either dessicated for 24 hours or dried for 2 days at room temperature. The dried feces were weighed, pulverized in a mortar and pestle, and transferred to alundum thimbles. The lipids were extracted in ethanol in Soxhlet extractors; repeated extraction of the residue revealed that $98 \%$ of the radioactivity was recovered in the first 24 hours, and, consequently, all the determinations in this study were performed on samples extracted 1 day. The ethanol extracts were transferred with washing to volumetric flasks and diluted to $100 \mathrm{ml}$ with ethanol. A $0.5-\mathrm{ml}$ aliquot was added to $10 \mathrm{ml} 0.5 \%$ diphenyloxazole in toluene and assayed for ${ }^{14} \mathrm{C}$; this fraction represented total sterol ${ }^{14} \mathrm{C}$. Another aliquot $(20 \mathrm{ml})$ was transferred to a $250-\mathrm{ml}$ Erlenmeyer flask, taken to dryness, and saponified in $10 \mathrm{ml}$ of $4 \mathrm{~N} \mathrm{NaOH}$ for 3 hours in an autoclave at 15 pounds pressure and $120^{\circ} \mathrm{C}$. An equal volume of ethanol was added, and the mixture was extracted two times with a fivefold excess of petroleum ether by shaking on an International bottle shaker. The combined petroleum ether extracts containing the fecal neutral sterols were backwashed with $10 \mathrm{ml}$ of ethanol-water $(1: 1)$, taken to dryness, and dissolved in ethanol. An aliquot was assayed for ${ }^{14} \mathrm{C}$ as before; this fraction contained the neutral sterols. The water-ethanol layer remaining after the petroleum ether extraction was acidified to $\mathrm{pH} 3$ with concentrated $\mathrm{H}_{2} \mathrm{SO}_{4}$ and extracted with ethyl ether. The ethyl ether extracts containing the fecal bile acids were then taken to dryness, redissolved in ethanol, and assayed for ${ }^{14} \mathrm{C}$ as before. Each sample was recounted after the addition of an internal standard, and, when necessary, corrections for quenching were made. By this technique recovery of the total ${ }^{14} \mathrm{C}$ was found to be greater than $92 \%$; in experiments with added cholesterol-4- ${ }^{14} \mathrm{C}$ and taurocholic acid${ }^{14} \mathrm{C}$, less than $5 \%$ of the cholesterol- $4-{ }^{14} \mathrm{C}$ was found to be carried over into the bile acid fractions.

Tissue, carcass, and diet analyses. The muscle biopsies in duplicate were dried overnight at $95^{\circ} \mathrm{C}$, allowed to cool in a dessicator, and weighed in tared containers. All other tissue analyses were done on undried samples. To each tissue and carcass sample were added 10 volumes of ethanol and one-tenth weight of potassium hydroxide per wet weight of sample. The solutions were saponified on a steam bath for 12 hours and diluted up to a measured volume. An aliquot of the alcoholic- $\mathrm{KOH}$ solution was then added to an equal volume of water, and the mixture was extracted twice with petroleum ether. Cholesteroldigitonides were formed from the petroleum ether residue, washed, and assayed for ${ }^{14} \mathrm{C}$ and chemical content as before.

Weighed aliquot portions of the dietary fats $(100 \mathrm{mg})$ were dissolved in acetone-ethanol, and the fatty acids were methylated by refluxing in $1 \% \mathrm{H}_{2} \mathrm{SO}_{4}$ in methanol for 1 hour. The methylated fatty acids were extracted into pentane, backwashed with $5 \% \mathrm{NaHCO}_{3}$ and then with water, taken to dryness under nitrogen, and analyzed by gas-liquid chromatography. The chromatography was performed on a Barber-Coleman gas-liquid chromatographic apparatus equipped with an ionization detector, and the conditions of the analysis were as follows: $5 \%$ polyethylene-glycol succinate on Gas-chrom $\mathrm{P}$ at a tem- 


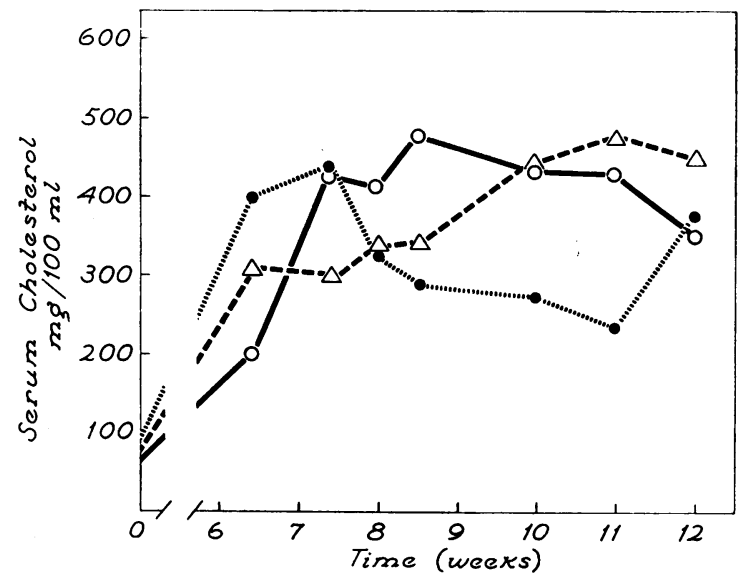

Fig. 1. The total SERUM Cholesterol In three RABBITS FED DIETS CONTAINING $10 \%$ HYDROGENATED COCONUT OIL FOR 12 WEEKS.

perature of $165^{\circ} \mathrm{C}$ with an argon flow of $100 \mathrm{ml}$ per minute at the outlet.

\section{Results}

The demonstration by Wigand ( 8 ) that the addition of saturated fat to a semisynthetic, cholesterol-free diet results in a moderate degree of hypercholesterolemia in the rabbit was confirmed in the present studies. The two dietary fats utilized in this study were hydrogenated coconut oil and corn oil. The hydrogenated coconut oil fed in this study contained no detectable linoleic acid and consisted primarily of lauric acid $(65 \%)$, myristic acid $(24 \%)$, palmitic acid $(7 \%)$, and stearic acid $(3 \%)$, whereas the corn oil contained predominantly linoleic $(63 \%)$, oleic $(26 \%)$, palmitic $(10 \%)$, and stearic $(<1 \%)$ acids. In Figure 1 are shown the serum cholesterol determinations on three rabbits allowed free access to a diet containing $10 \%$ hydrogenated coconut oil for 12 weeks. After 6 weeks of feeding, a modest degree of hypercholesterolemia was evident in each animal (195 to $400 \mathrm{mg}$ per $100 \mathrm{ml}$ ), and an elevated, although somewhat variable, serum cholesterol persisted in each animal until the end of the study. At no time did the extreme degree of hypercholesterolemia observed in a few of Wigand's rabbits develop in the present studies. A reason for this difference may be that after 6 weeks of ingesting the purified diets, the rabbits in the present study were usually placed in wooden rabbit collars to prevent coprophagy. The magnitude of co- prophagy in this species has been well documented, amounting in some estimates to as much as 50 to $90 \%$ of the feces excreted (27). Thus, in an animal excreting $25 \mathrm{mg}$ of endogenous cholesterol per day, coprophagy could provide a significant means 'of cholesterol intake; therefore, this possible source of dietary cholesterol was carefully excluded during the balance studies.

To investigate the mechanisms of the cholesterol lowering effects of unsaturated fats, attention was first directed to cholesterol excretion and degradation. Previous studies in this laboratory have demonstrated that the isotopic steady state can be utilized for the quantification of the two major pathways of cholesterol elimination (21). As demonstrated in Figure 2, when capsules containing cholesterol- $4-{ }^{14} \mathrm{C}$ are implanted subcutaneously, the specific activity of the serum cholesterol rises with time and eventually approaches a plateau. When such a near steady state is attained, the degradation and excretion products of cholesterol could be quantified as follows: neutral sterol excretion (milligrams per day) $=$ total ${ }^{14} \mathrm{C}$ recovered in fecal neutral sterols (counts per minute per day)/specific activity of serum cholesterol (counts per minute per milligram); bile acid excretion (milligrams per day) $=$ total ${ }^{14} \mathrm{C}$ recovered in fecal bile acids (counts per minute per day)/specific activity of serum cholesterol (counts per minute per milligram). These two end products represent the significant cholesterol excretory pathways (21).

In Figure 3 is shown an experiment in which this technique was utilized for the measurement of cholesterol excretion and degradation in a rabbit

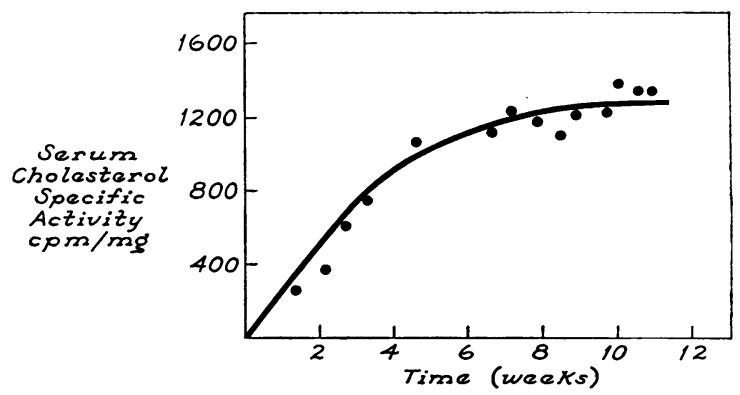

Fig. 2. The change in the SPecific activity of TOTAL SERUM CHOLESTEROL WITH TIME AFTER THE SUBCUTANEOUS IMPLANTATION OF A CAPSULE CONTAINING CHOLESTEROL-4- ${ }^{14} \mathrm{C}$ (47,700 CPM PER MG). 


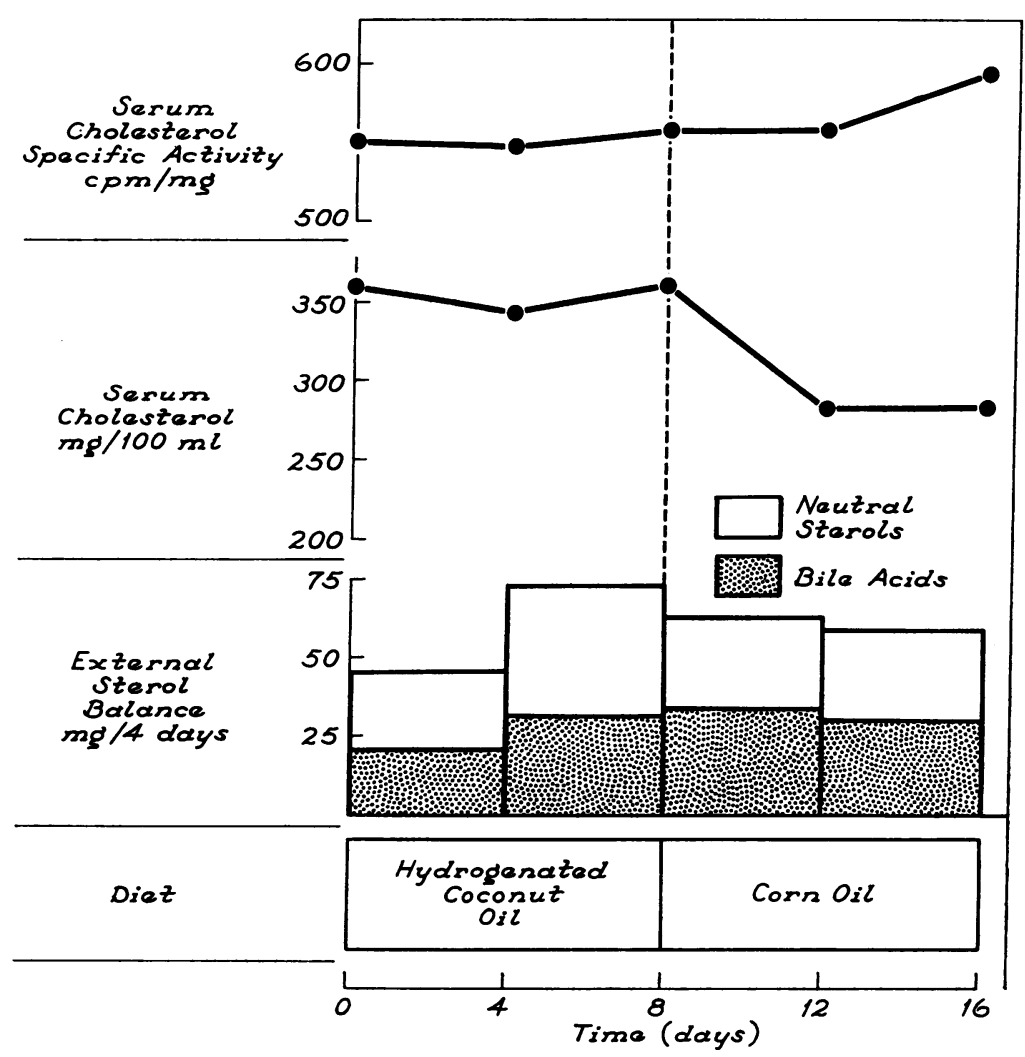

Fig. 3. The influence of a Change in dietary fat From $10 \%$ hydroGENATED COCONUT OIL TO $10 \%$ CORN OIL IN A RABBIT IN THE ISOTOPIC STEADY STATE ON THE SPECIFIC ACTIVITY OF SERUM CHOLESTEROL, SERUM CHOLESTEROL CONCENTRATION, AND THE EXTERNAL STEROL BALANCE (REPRESENTING THE TOTAL OF NEUTRAL STEROL AND BILE ACID EXCRETION). This animal had been fed the coconut oil diet for 10 weeks and implanted with a cholesterol-4- ${ }^{14} \mathrm{C}$ pellet for 8 weeks before the beginning of the study.

fed different dietary fats. This rabbit had been fed a diet containing hydrogenated coconut oil for 10 weeks and had been implanted with a cholesterol- ${ }^{14} \mathrm{C}$ pellet for 8 weeks. As shown in the top line, the serum cholesterol specific activity had reached a plateau $(560,530$, and $570 \mathrm{cpm}$ per $\mathrm{mg}$ ), and the serum cholesterol level was also relatively constant $(360,340$, and $350 \mathrm{mg}$ per $100 \mathrm{ml})$. When the diet was changed from $10 \%$ hydrogenated coconut oil to $10 \%$ corn oil, the serum cholesterol promptly fell $70 \mathrm{mg}$ per $100 \mathrm{ml}$ (from 350 to 280). Despite this abrupt fall in blood cholesterol, as shown in the bars at the bottom of the diagram, there was no increase either in the excretion of bile acids or neutral sterols for as long as 8 days after the change in dietary fats. The absence of a rise in sterol excretion is noteworthy, since a fall in serum cholesterol of $70 \mathrm{mg}$ per 100 $\mathrm{ml}$ in a $1.5-\mathrm{kg}$ rabbit represented a total disappearance of approximately $35 \mathrm{mg}$ of cholesterol from the serum; this quantity of sterol, if excreted during the balance study, would have been detectable by the methods used in these experiments.

Eight similar experiments are summarized in Figure 4; the serum cholesterol of each animal fell 60 to $150 \mathrm{mg}$ per $100 \mathrm{ml}$ when the dietary fat was changed from hydrogenated coconut oil to corn oil (the first column). In none of the six studies in which the balance studies were completed did the excretion of cholesterol and its degradation products rise (the last column), nor could significant changes be demonstrated in the mean excretion values ( $70 \pm 38$ and $72 \pm 37 \mathrm{mg}$ per 4 days). It was concluded from these experiments that the fall 


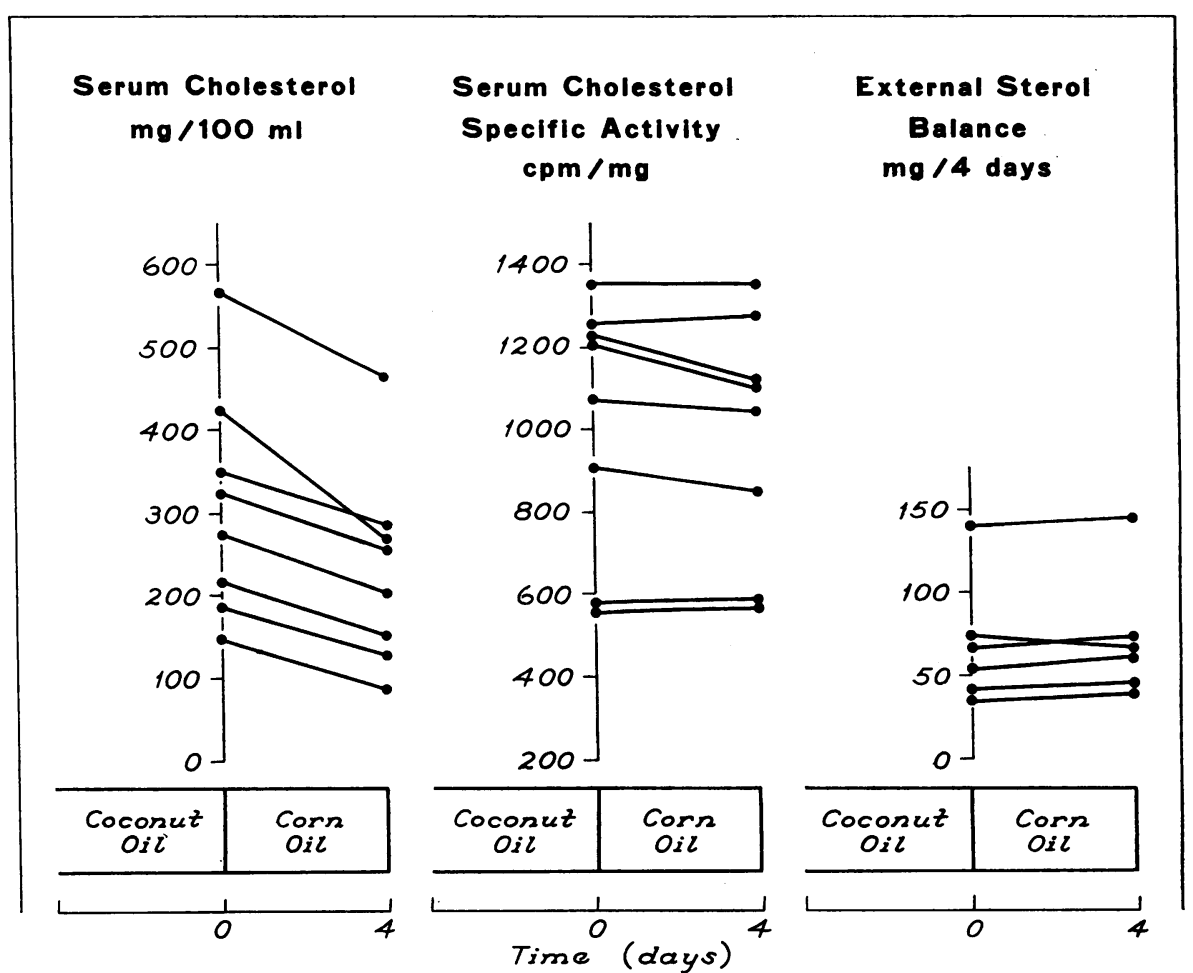

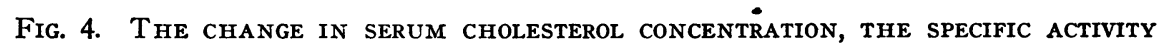
OF SERUM CHOLESTEROL, AND THE EXTERNAL STEROL BALANCE IN EIGHT RABBITS IN AN ISOTOPIC STEADY STATE OVER A 4-DAY INTERVAL AFTER A SHIFT IN DIETARY FAT FROM HYDROGENATED COCONUT OIL TO CORN OIL.

in rabbit serum cholesterol induced by unsaturated fats cannot be explained by any effects on the excretion or degradation of cholesterol. Furthermore, the serum cholesterol specific activity did not rise during the time in which cholesterol levels fell (middle column), suggesting that cholesterol synthesis also was not inhibited by this dietary change.

To clarify further the possible role of altered rates of cholesterol synthesis in this effect, a variety of experiments was performed in which cholesterol turnover was measured after single injections of cholesterol ${ }^{14} \mathrm{C}$. As shown in Figure 5, when adequate time was allowed for equilibration of the isotope, the change in dietary fat resulted in no change whatsoever in cholesterol- ${ }^{14} \mathrm{C}$ turnover [ $t_{t}$ (turnover time) $=\mathbf{2 0 . 9}$ days] despite the fact that serum cholesterol in this experiment fell from a mean of $260 \mathrm{mg}$ per $100 \mathrm{ml}$ to $145 \mathrm{mg}$ per 100 ml. If a blood volume of $5 \%$ of the body weight is assumed, it can be calculated that approximately
$56 \mathrm{mg}$ of cholesterol disappeared from the bloodstream during the first 2 days after the change in diet. Since neither cholesterol excretion or degradation nor cholesterol synthesis (as reflected by the unaltered turnover time in animals in which excretion and degradation are unchanged) was altered by the feeding of unsaturated fat, it follows that a redistribution of cholesterol between serum and tissues must have occurred.

To investigate the possible site of such a redistribution of serum cholesterol, both the total and miscible pools of cholesterol were measured 1 day and 26 days after the injection of radioactive cholesterol; the average values for eight such studies have been plotted in Figure 6. In this graph the term "miscible cholesterol" refers to the counts of radioactive cholesterol recovered in each tissue divided by the specific activity of the serum cholesterol at the time of death. Even at the 1-day time interval about $30 \%$ of the total body cholesterol had equilibrated with that of the serum. It 
should be noted that, due to the enormous size of the total body cholesterol pool, the cholesterol that had disappeared from the serum on feeding unsaturated fats represented only a small percentage (averaging about $10 \%$ ) of this rapidly miscible fraction, and it is quite apparent that a shift of cholesterol from serum to cells could cause dramatic changes in the serum concentration under circumstances in which only slight changes might be demonstrated in the tissue content. Indeed, after 26 days of equilibration, the miscible pool accounted for approximately two-thirds of the total body cholesterol, indicating the presence of a very large pool for the possible redistribution of serum cholesterol.

It is apparent from Figure 6 that the muscle and skeleton contain both the largest single pool of cholesterol in the body and the largest rapidly miscible fraction. Consequently, our attention was next directed to an examination of these tissues. In an attempt to obtain some evidence for possible changes in intracellular cholesterol concentration during fat feeding, muscle biopsies were obtained from the thigh before and after the shift from coconut oil to corn oil. The muscle cholesterol content rose slightly in the animal shown in Figure 5

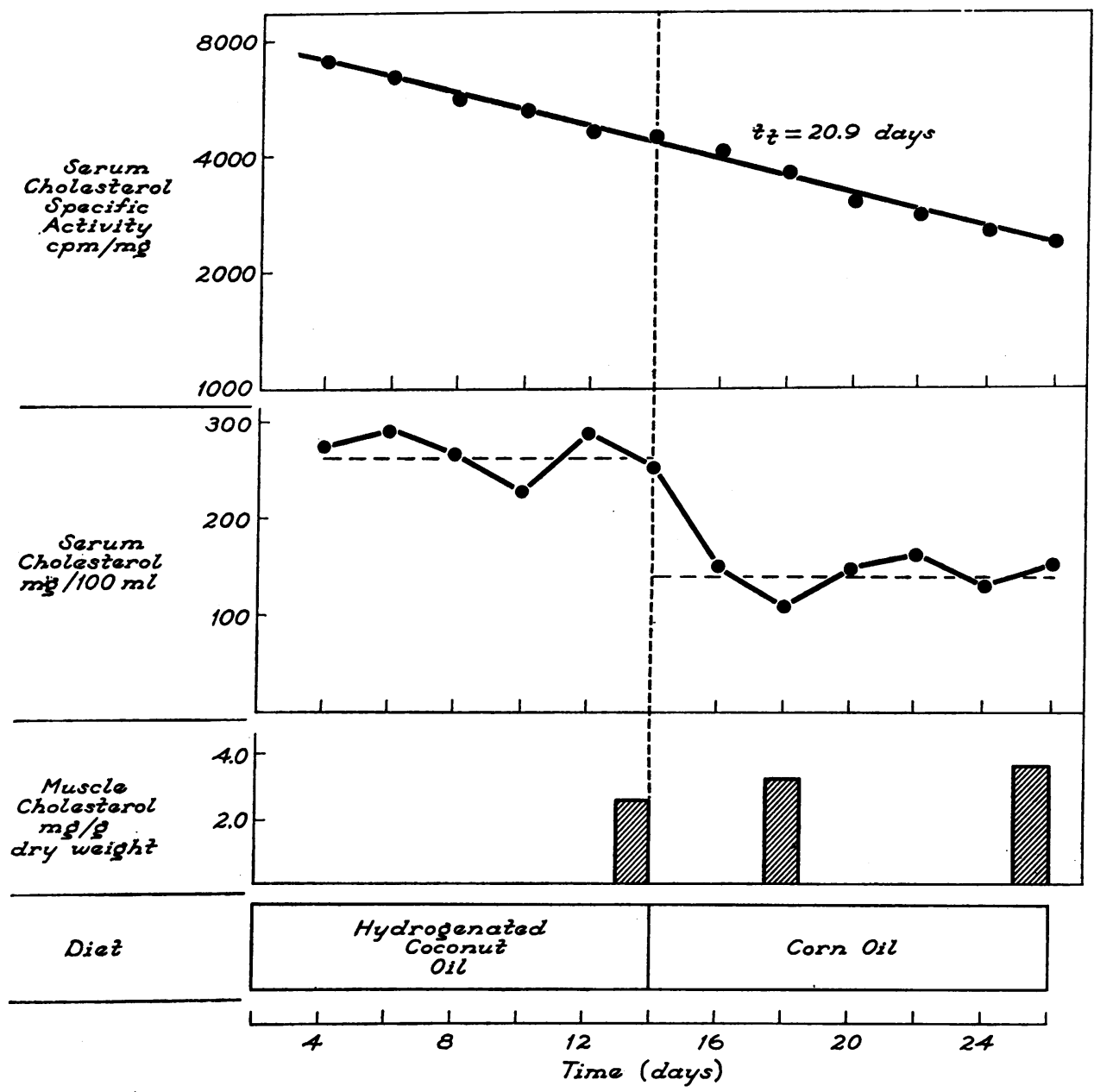

Fig. 5. The influence of a change in dietary fat from hydrogenated coconut oil to CORN OIL ON THE TURNOVER OF SERUM CHOLESTEROL, THE CONCENTRATION OF SERUM CHOLESTEROL, AND THE CONCENTRATION OF MUSCLE CHOLESTEROL. The turnover time $\left(t_{t}\right)$ of total serum cholesterol has been plotted for days 4 to 26 after a single intravenous injection of cholesterol-4- ${ }^{14} \mathrm{C}$, and muscle biopsies were obtained from the thigh at the time of and 4 and 12 days after the shift in dietary fat. 


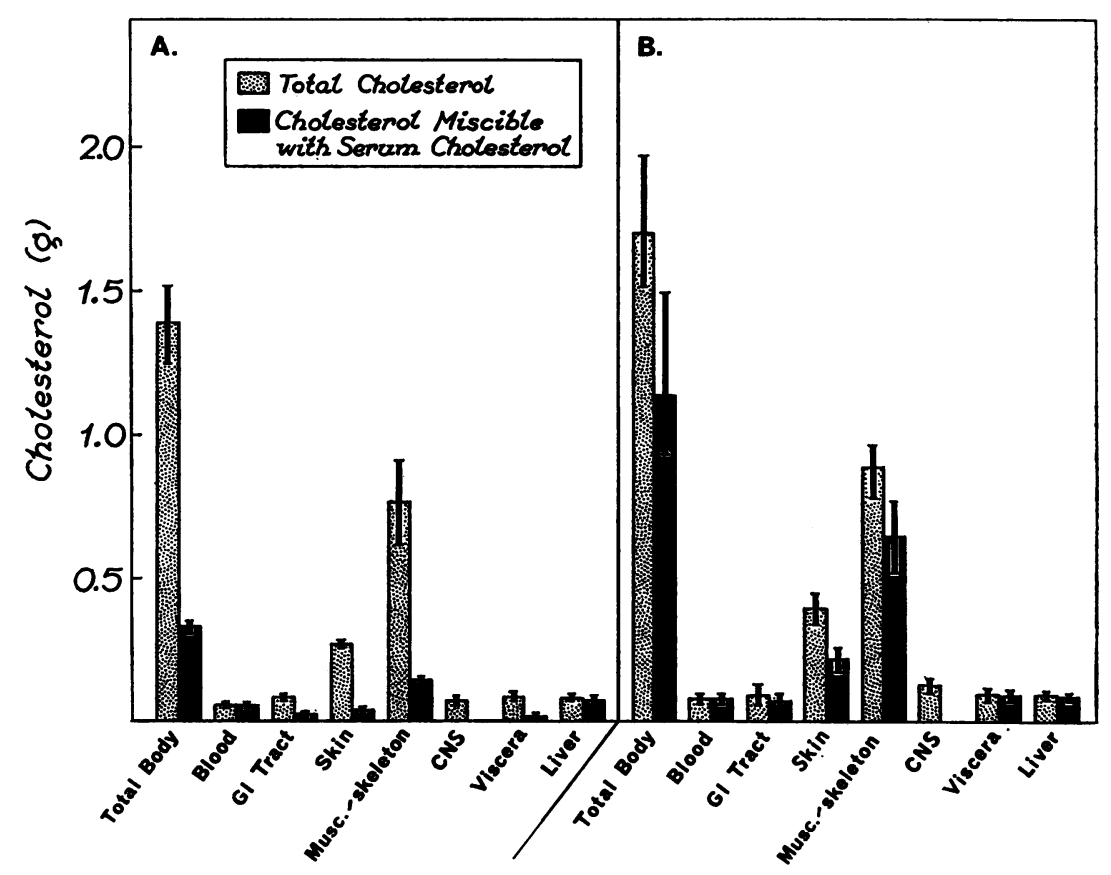

Fig. 6. THE DISTRIBUtion OF MISCIBLE AND tOTAL CHOLESTEROL THROUGHOUT THE ENTIRE CARCASS OF THE RABBIT AFTER THE ADMINISTRATION OF RADIOACTIVE CHOLESTEROL. A, 1 day after the administration of radioactive cholesterol; B, 26 days after the administration of cholesterol- $4-{ }^{14} \mathrm{C}$. In each instance total cholesterol represents a direct chemical analysis of the cholesterol content, and cholesterol miscible with serum cholesterol represents the figure derived by dividing the radioactive cholesterol recovered from each tissue (counts per minute) by the specific activity of the serum cholesterol (counts per minute per milligram). The bars represent average values and ranges for a total of eight rabbits weighing from 1.2 to $2.0 \mathrm{~kg}$. CNS = central nervous system.

from 2.5 to $3.3 \mathrm{mg}$ per $\mathrm{g}$ of dry weight during the first 4 days of corn oil feeding. At the end of this experiment the muscle was dissected from the carcass, and the total dry weight of the recovered muscle was found to be about $75 \mathrm{~g}$. In this animal the change in muscle cholesterol was therefore of sufficient magnitude to account for a storage of $66 \mathrm{mg}$ of cholesterol and could account, consequently, for the entire amount that had disappeared from the serum of this animal.

Ten similar turnover and biopsy experiments are summarized in Figure 7. In these ten animals the mean serum cholesterol concentration fell an average of $76 \mathrm{mg}$ per $100 \mathrm{ml}$ when the dietary fat was changed from coconut oil to corn oil, whereas in none of the animals was any change in cholesterol turnover time demonstrated. As shown in Table I, the muscle mass of each animal was dissected and weighed at the end of the experiment.
The increase in muscle cholesterol concentration, the estimated quantity of cholesterol that had disappeared from the serum, and the increase in total cholesterol content of the muscle mass have been plotted in the three right-hand columns of Table I. In nine of the animals muscle cholesterol content rose slightly from 0.2 to as much as $1 \mathrm{mg}$ per g dry weight. Although rather consistent in individual animals, the change in mean muscle cholesterol in these animals was not significant $(2.6 \pm$ $0.4 \mathrm{mg}$ per $\mathrm{g}$ and $3.1 \pm 0.7 \mathrm{mg}$ per $\mathrm{g}$ ). However, due to the enormous size of the muscle mass, these slight changes in concentration were of sufficient magnitude when projected to the entire skeletal muscle mass to account for a significant amount of the cholesterol that disappeared from the serum. Not only was the mean increase in muscle cholesterol in the nine rabbits sufficient to account for the mean disappearance from the serum, but 


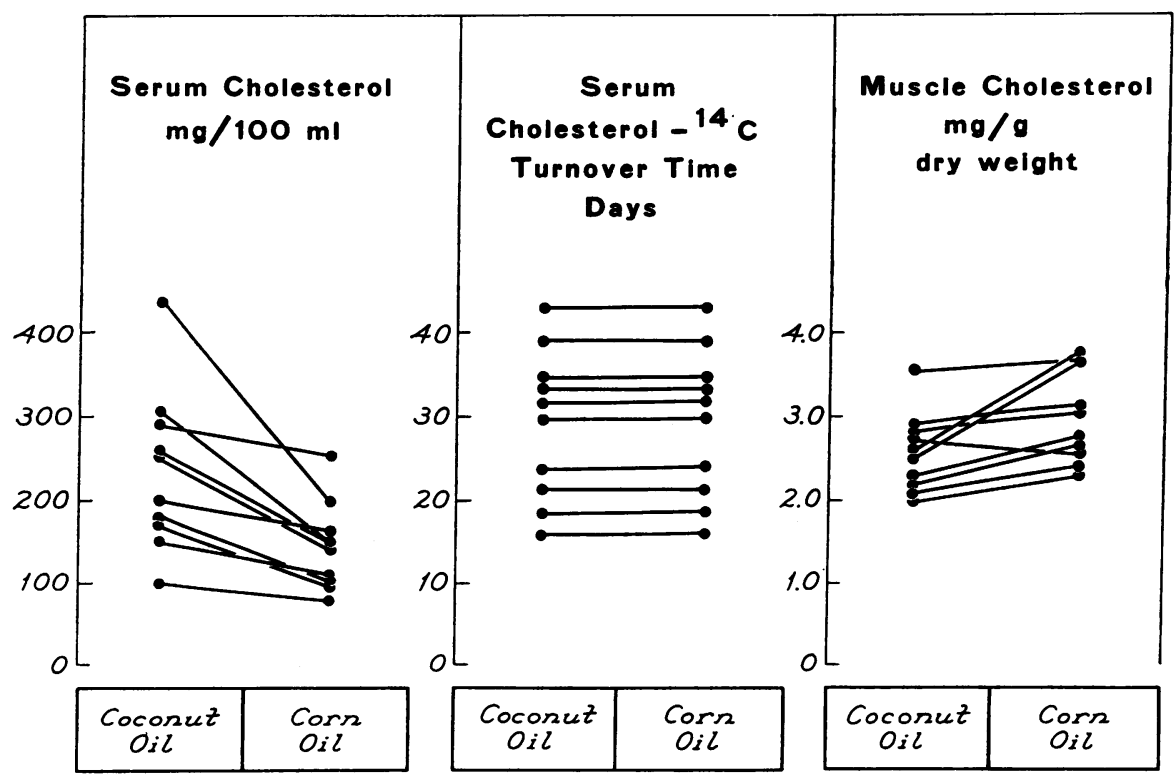

Fig. 7. THE INFLUENCE OF A CHANGE IN DIETARY FAT FROM HYDROGENATED COCONUT OIL TO CORN OIL ON THE SERUM CHOLESTEROL CONCENTRATION AND TURNOVER TIME AND THE MUSClE CHOLESTEROL CONCENTRATION IN TEN RABBITS. The serum cholesterol concentration and muscle cholesterol concentration have been plotted for the first 4 days after the shift in dietary fats, whereas the turnover times have been plotted for either 26 or 40 days after the injection of a single dose of cholesterol-4- ${ }^{14} \mathrm{C}$.

in most animals the increase in muscle cholesterol, although slight in magnitude, was sufficient to account for a major portion of that which disappeared from the serum. Obviously, undue emphasis should not be placed on these very rough calculations; not only are the changes in concentra- tion insignificant, but, in addition, the thigh muscle is not necessarily representative of the entire muscle pool. The calculations have been made only to emphasize that shifts of cholesterol from serum to a large intracellular pool might readily account for significant changes in the serum con-

TABLE I

Relation between drop in serum cholesterol and increase in muscle cholesterol after change from saturated to unsaturated fat

\begin{tabular}{|c|c|c|c|c|c|c|}
\hline $\begin{array}{c}\text { Rabbit } \\
\text { no. }\end{array}$ & Weight & $\begin{array}{l}\text { Dry weight } \\
\text { of muscle }\end{array}$ & $\begin{array}{c}\text { Decrease in } \\
\text { serum } \\
\text { cholesterol }\end{array}$ & $\begin{array}{c}\text { Increase in } \\
\text { muscle } \\
\text { cholesterol }\end{array}$ & $\begin{array}{c}\text { Estimated } \\
\text { total } \\
\text { cholesterol } \\
\text { disappeared } \\
\text { from } \\
\text { serum }\end{array}$ & $\begin{array}{c}\text { Estimated } \\
\text { total } \\
\text { increase } \\
\text { in muscle } \\
\text { cholesterol }\end{array}$ \\
\hline $\begin{array}{r}1 \\
2 \\
3 \\
4 \\
5 \\
6 \\
7 \\
8 \\
9 \\
10\end{array}$ & $\begin{array}{l}\mathrm{kg} \\
1.2 \\
1.4 \\
1.4 \\
1.7 \\
1.2 \\
1.6 \\
1.3 \\
1.9 \\
1.5 \\
1.3\end{array}$ & $\begin{array}{r}g \\
79 \\
87 \\
75 \\
110 \\
54 \\
84 \\
74 \\
123 \\
86 \\
72\end{array}$ & $\begin{array}{c}m g / 100 m l \\
115 \\
150 \\
115 \\
42 \\
52 \\
28 \\
115 \\
42 \\
65 \\
38\end{array}$ & $\begin{array}{c}m g / g d r y \text { wt } \\
0.24 \\
0.44 \\
0.88 \\
0.32 \\
1.00 \\
0.27 \\
0.16 \\
0.25 \\
0.20 \\
-0.18\end{array}$ & $\begin{array}{l}m g \\
41 \\
63 \\
48 \\
21 \\
19 \\
14 \\
45 \\
24 \\
29 \\
15\end{array}$ & $\begin{array}{l}m g \\
19 \\
38 \\
66 \\
35 \\
54 \\
23 \\
12 \\
31 \\
17\end{array}$ \\
\hline Average & & & & & 32 & 30 \\
\hline
\end{tabular}


centration without necessarily causing comparable changes in the concentration of the larger intracellular pool.

\section{Discussion}

In the present series of studies the influence of dietary fats on several aspects of cholesterol metabolism has been examined in the rabbit. Under circumstances in which any possible influence on the absorption of exogenous cholesterol was excluded by providing the animals with a cholesterolfree diet and by preventing coprophagy, it has been possible to confirm the previous observations (810) that, as in man, the feeding of saturated fats to this animal results in a sustained elevation of the serum cholesterol and furthermore that this hypercholesterolemia is promptly reversed when unsaturated fats are substituted in the diet. Apparently, therefore, the rabbit is an adequate experimental animal in which to study the mechanisms of this effect of fat on the serum cholesterol. Because the reversal of the saturated fat-induced hypercholesterolemia is the more rapid of the two effects, advantage has been taken of this sudden fall in serum cholesterol to investigate three aspects of cholesterol metabolism: cholesterol excretion and degradation, cholesterol synthesis as indicated by cholesterol turnover, and the possible anatomical sites for the redistribution of cholesterol between serum and the cells.

Utilizing an isotopic steady state technique for the simultaneous quantification of the excretion of cholesterol and its neutral and acidic transformation products, we have been able to demonstrate that even after abrupt, marked changes in the serum cholesterol, no change occurs in either bile acid or neutral sterol excretion. The present results do not confirm previous reports that unsaturated fats accelerate the excretion of either neutral sterols $(13,14)$ or bile acids $(11,12,14)$. These results are in agreement with the findings of Spritz, Ahrens, and Grundy (15) who, utilizing a combination of careful balance and chemical techniques, were also unable to demonstrate any fat-induced changes in the excretion or degradation of cholesterol in man. Quantification of the two pathways of cholesterol elimination in the intact animal, despite a common channel of excretion, has proved to be a difficult problem for several reasons (21). First, after reaching the lumen of the intestine both bile acids and cholesterol are transformed by bacterial action into a variety of different products, some of which cannot be measured by standard techniques. Second, an enterohepatic circulation exists both for bile acids, and to a lesser extent for cholesterol, with the result that changes in the rate of sterol excretion may not be quantitatively reflected in the external balance until a new steady state has been attained. Third, in the intestinal lumen endogenous cholesterol is mixed with dietary sterols so that the fecal pool represents a mixture of derivatives of endogenous and exogenous cholesterol and of dietary sterols other than cholesterol; bile acids also may be formed from noncholesterol sterols of dietary origin. Finally, short-term isotopic techniques, because of the varying pool sizes and varying turnover rates of the products involved, may not always provide valid quantitative data. The only techniques at the present time that circumvent these difficulties are the isotopic steady state technique (21) and the combination of balance and chromatographic techniques that has been developed by Grundy, Ahrens, and Miettinen $(28,29)$. On the basis of the present studies utilizing the isotopic steady state technique, it seems safe to conclude that the feeding of unsaturated fats results in a lowering of the serum cholesterol level in the rabbit without affecting either the excretion or degradation of cholesterol.

The present studies also show that the feeding of unsaturated fat does not influence cholesterol synthesis in the rabbit as reflected in an unaltered turnover rate determined by plotting the decay curve after a single intravenous injection of cholesterol- $-4{ }^{-14} \mathrm{C}$. This finding is in agreement with the demonstration that in the isotopic steady state the specific activity of serum cholesterol did not rise after the abrupt fall in the cholesterol level as would have been expected if the feeding of unsaturated fat lowered serum cholesterol by inhibiting synthesis. These results also agree with previous experiments in which no difference in the effects of saturated and unsaturated fats on hepatic cholesterol synthesis could be demonstrated $(16,17)$, but do not agree with a reported enhancement of cholesterol synthesis by the feeding of polyunsaturated fats (19). The turnover time in the present studies for rabbit serum cholesterol was longer (average 25.4 days) than has previously been reported (30). This difference is probably due to the fact 
that our studies were carried out over a very long period of time in order to be certain that the specific activity declined at an exponential rate. As has been reported in man by Hellman, Rosenfeld, and Gallagher (31) and by Chobanian, Burrows, and Hollander (32), a prolonged period of study is necessary for measurement of the turnover rate of cholesterol in slowly exchanging compartments. In view of the apparent single exponential decay rate between 8 and 28 days in the rabbit, the determination of turnover time in these compartments is probably valid under these conditions.

Since no evidence could be obtained in support of the possibility that unsaturated fats lowered the serum cholesterol of the rabbit either by inhibiting cholesterol synthesis or by accelerating cholesterol degradation or excretion, we concluded that unsaturated fats must effect a redistribution of cholesterol between serum and tissues. A similar conclusion has been reached by Spritz and associates (15) and by Frantz and Carey (19) as the result of studies in man. On the other hand, measurements of changes in the concentration of liver cholesterol in man indicated that the liver cholesterol decreased when unsaturated fat was fed to human subjects, and this tissue was probably not the site for such storage (19). In an attempt to evaluate other possible sites for cholesterol deposition, we assayed the rapidly miscible pool in a rabbit and found that as early as 24 hours after a single injection of radioactive cholesterol, approximately $40 \%$ of the miscible pool of cholesterol could be found in the muscle and skeleton. Since this compartment represents not only a large fraction of the rapidly miscible pool but in addition is the largest absolute pool of cholesterol of the body, the muscle cholesterol content was measured before and after changes in the dietary fat. It was not possible to demonstrate that significant increases in the muscle cholesterol concentration occurred during the feeding of unsaturated fats. Due to the large size of the muscle mass, however, it could be calculated that trivial changes in cholesterol concentration might be sufficient to account for virtually the entire fall in serum cholesterol of the rabbit induced by unsaturated fat. If, indeed, unsaturated fat does lower serum cholesterol by effecting a redistribution between serum and the tissues and if cholesterol excretion and degradation and cholesterol synthesis remain unchanged. then a permanent lowering of serum cholesterol could result. The mechanisms by which such a redistribution might be effected are at present unclear, and it is entirely possible that tissues other than muscle might participate in such effects.

No conclusions can be drawn about the value of lowering the serum cholesterol under circumstances in which the total body levels are uninfluenced. If, as suggested by Newman and Zilversmit (33), the concentration of cholesterol in the serum bathing the aortic intima is critical in determining the rate of atherogenesis, such a redistribution might be of real therapeutic value; the demonstration by Wigand (8) that rabbits fed cholesterol-free diets containing saturated fats for long periods do develop atherosclerosis is in keeping with this view.

\section{Summary}

The observation that the serum cholesterol of rabbits on cholesterol-free diets falls in response to isocaloric substitution of unsaturated for saturated fats has been confirmed. The present experiments have been interpreted as clearly excluding the possibility that unsaturated fats lower the serum cholesterol in the rabbit by influencing either cholesterol synthesis or cholesterol excretion or degradation. Indirect evidence has been accrued which suggests that unsaturated fats effect a redistribution of cholesterol between serum and tissues.

\section{Acknowledgments}

The technical assistance of Mr. George T. Crowley, Mrs. Mary Beth Neal, and Mrs. Joanne Sherwood in the performance of these studies is gratefully acknowledged.

\section{References}

1. Bieberdorf, F. A., and J. D. Wilson. Influence of unsaturated fat on cholesterol-C $\mathrm{C}^{14}$ metabolism in the isotopic steady state in the rabbit (abstract). Clin. Res. 1964, 12, 39.

2. Bieberdorf, F. A., and J. D. Wilson. Influence of unsaturated fat on cholesterol- $\mathrm{C}^{\mathbf{1 4}}$ metabolism in the isotopic steady state in the rabbit (abstract). Clin. Res. 1964, 12, 262.

3. Kinsell, L. W., J. Partridge, L. Boling, S. Margen, and G. Michaels. Dietary modification of serum cholesterol and phospholipid levels. J. clin. Endocr. 1952, $12,909$.

4. Groen, J., B. K. Tjiong, C. E. Kamminga, and A. F. Willebrands. The influence of nutrition, individuality and some other factors including various forms 
of stress, on the serum cholesterol; an experiment of nine months duration in 60 normal human volunteers. Voeding 1952, 13, 556.

5. Kinsell, L. W., G. D. Michaels, J. W. Partridge, L. A. Boling, H. E. Balch, and G. C. Cochrane. Effect upon serum cholesterol and phospholipids of diets containing large amounts of vegetable fat. J. clin. Nutr. 1953, 1, 224.

6. Ahrens, E. H., Jr., J. Hirsch, W. Insull, Jr., T. T. Tsaltas, R. Blomstrand, and M. L. Peterson. The influence of dietary fats on serum-lipid levels in man. Lancet 1957, 1, 943.

7. Malmros, H., and G. Wigand. The effect on serumcholesterol of diets containing different fats. Lancet 1957, 2, 1 .

8. Wigand, G. Production of hypercholesterolemia and atherosclerosis in rabbits by feeding different diets without supplementary cholesterol. Acta med. scand. 1960, 166 (suppl. 351).

9. Lambert, G. F., J. P. Miller, R. T. Olsen, and D. V. Frost. Hypercholesteremia and atherosclerosis induced in rabbits by purified high fat rations devoid of cholesterol. Proc. Soc. exp. Biol. (N. Y.) 1958, 97, 544.

10. Steiner, A., A. Varsos, and P. Samuel. Effect of saturated and unsaturated fats on the concentration of serum cholesterol and experimental atherosclerosis. Circulat. Res. 1959, 7, 448.

11. Gordon, H., B. Lewis, L. Eales, and J. F. Brock. Effect of different dietary fats on the faecal endproducts of cholesterol metabolism. Nature (Lond.) 1957, 180, 923.

12. Haust, H. L., and J. M. R. Beveridge. Effect of varying type and quantity of dietary fat on the fecal excretion of bile acids in humans subsisting on formula diets. Arch. Biochem. 1958, 78, 367.

13. Hellman, L., R. S. Rosenfeld, W. Insull, Jr., and E. H. Ahrens, Jr. Intestinal excretion of cholesterol : a mechanism for regulation of plasma levels (abstract). J. clin. Invest. 1957, 36, 898.

14. Moore, R. B., J. T. Anderson, A. Keys, and I. D. Frantz, Jr. Effect of dietary fat on the fecal excretion of cholesterol and its degradation products in human subjects. J. Lab. clin. Med. 1962, 60,1000 .

15. Spritz, N., E. H. Ahrens, Jr., and S. Grundy. Sterol balance in man as plasma cholesterol concentrations are altered by exchanges of dietary fats. J. clin. Invest. 1965, 44, 1482.

16. Wilson, J. D., and M. D. Siperstein. Effect of saturated and unsaturated fats on hepatic synthesis and biliary excretion of cholesterol by the rat. Amer. J. Physiol. 1959, 196, 599.

17. Linazasoro, J. M., R. Hill, F. Chevallier, and I. L. Chaikoff. Regulation of cholesterol synthesis in the liver: the influence of dietary fats. J. exp. Med. 1958, 107, 813.
18. Kinsell, L. W., G. D. Michaels, G. Walker, and J. Conklin. Cholesterol synthesis in normal and abnormal human subjects (abstract). Circulation 1960, 22, 661.

19. Frantz, I. D., Jr., and J. B. Carey, Jr. Cholesterol content of human liver after feeding of corn oil and hydrogenated coconut oil. Proc. Soc. exp. Biol. (N. Y.) 1961, 106, 800.

20. Avigan, J., and D. Steinberg. Effects of saturated and unsaturated fat on cholesterol metabolism in the rat. Proc. Soc. exp. Biol. (N. Y.) 1958, 97, 814.

21. Wilson, J. D. The quantification of cholesterol excretion and degradation in the isotopic steady state in the rat: the influence of dietary cholesterol. J. Lipid Res. 1964, 5, 409.

22. Kulwich, R., L. Struglia, and P. B. Pearson. The effect of coprophagy on the excretion of B vitamins by the rabbit. J. Nutr. 1953, 49, 639.

23. Meier, J. R., M. D. Siperstein, and I. L. Chaikoff. $\mathrm{C}^{14}$-cholesterol. IV. Oxidation of carbons 4 and 26 to carbon dioxide by surviving tissues. J. biol. Chem. 1952, 198, 105.

24. Zilversmit, D. B., C. Entenman, and M. C. Fishler. On the calculation of "turnover time" and "turnover rate" from experiments involving the use of labeling agents. J. gen. Physiol. 1942, 26, 325.

25. Sperry, W. M., and M. Webb. A revision of the Schoenheimer-Sperry method for cholesterol determination. J. biol. Chem. 1950, 187, 97.

26. Siperstein, M. D., M. E. Jayko, I. L. Chaikoff, and W. G. Dauben. Nature of the metabolic products of $\mathrm{C}^{14}$-cholesterol excreted in bile and feces. Proc. Soc. exp. Biol. (N. Y.) 1952, 81, 720.

27. Eden, A. Coprophagy in the rabbit. Nature (Lond.) 1940, 145, 36.

28. Grundy, S. M., E. H. Ahrens, Jr., and T. A. Miettinen. Quantitative isolation and gas-liquid chromatographic analysis of total fecal bile acids. J. Lipid Res. 1965, 6, 397.

29. Miettinen, T. A., E. H. Ahrens, Jr., and S. M. Grundy. Quantitative isolation and gas-liquid chromatographic analysis of total dietary and fecal neutral steroids. J. Lipid Res. 1965, 6, 411.

30. Biggs, M. W., and D. Kritchevsky. Observations with radioactive hydrogen $\left(\mathrm{H}^{3}\right)$ in experimental atherosclerosis. Circulation 1951, 4, 34.

31. Hellman, L., R. S. Rosenfeld, and T. F. Gallagher. Cholesterol synthesis from $\mathrm{C}^{\mathbf{1 4}}$-acetate in man. $\mathrm{J}$. clin. Invest. 1954, 33, 142.

32. Chobanian, A. V., B. A. Burrows, and W. Hollander. Body cholesterol metabolism in man. II. Measurement of the body cholesterol miscible pool and turnover rate. J. clin. Invest. 1962, 41, 1738.

33. Newman, H. A. I., and D. B. Zilversmit. Quantitative aspects of cholesterol flux in rabbit atheromatous lesions. J. biol. Chem. 1962, 237, 2078. 